\title{
Políticas públicas de la migración: elementos a considerar para la administración del fenómeno migratorio en el Pacífico colombiano
}

Nadia García Sicard ${ }^{1}$

\section{Introducción}

El fenómeno de la migración alrededor del mundo en las últimas dos décadas, tras la expansión de la globalización y los desafíos que esta atrae -económicos y medioambientales especialmente-, han sido estudiados tendencialmente de manera aislada, señalando como principal problema el fenómeno, sin interconectarlo con las causas y las soluciones al mismo.

Analizar los desafíos de la globalización como la pobreza, la desigualdad, los cambios demográficos y ambientales, las crisis sociales, políticas e institucionales, aparte del fenómeno de la migración, deja de lado la complejidad, la interconexión y los procesos a multinivel de los cambios de tipo demográfico que vienen transformando a los países de donde emigran las personas como los receptores de inmigrantes.

En de la Teoría de la Migración, Everett S. Lee (1966) plantea cuatro factores del "acto de migrar": 1. Factores asociados con el área de origen, 2. Factores asociados con el sitio de destino, 3. Obstáculos intervinientes y 4. Factores personales. Dentro de los tres primeros existen situaciones positivas (+), negativas (-) e indiferentes (o)

$1 \quad$ Magíster en Geografía Humana de la Universidad Tübingen, Alemania. Profesional en Relaciones Internacionales. Profesora de la Universidad Santo Tomás e Investigadora de la Facultad de Relaciones Internacionales (UMNG). Nadiagarcia@usantotomas.edu.co 
que hacen de la migración una situación en la mayoría de sus casos inexacta y variada dependiendo de cada persona y circunstancia.

El fenómeno actual de la migración intercontinental en Latinoamérica hacia Estados Unidos se puede analizar desde los casos 1 y 2, en los que los factores (-) del sitio de origen son asociados con la inestabilidad económica, la desigualdad y la falta de oportunidades; mientras que al sitio de destino, en este caso Estados Unidos, se le asocia con factores $(+)$ como el "sueño americano" y las oportunidades de conseguir una estabilidad económica. Sin embargo, este análisis deja por fuera las complejidades que se afrontan más allá de estos factores y las responsabilidades y desafíos que acarrea un país bien sea receptor o de tránsito. En este sentido, en Colombia se presenta un incremento en la migración extracontinental bajo la dinámica de inmigrante en tránsito que no busca permanecer en el país sino que utiliza la región pacífica como ruta hacia Norteamérica.

En este artículo se analizan los factores referentes a los "obstáculos intervinientes" que se presentan al atravesar la ruta migrante del Pacífico de sur (Ecuador), pasando por Colombia hacia el norte (México) para alcanzar su destino final: Estados Unidos. Dentro de los obstáculos intervinientes se pueden encontrar varios factores que merecen ser estudiados para comprender la complejidad de este actual fenómeno migratorio. En esta ocasión el principal obstáculo interviniente es el vacío de políticas públicas de migraciones irregulares en la región pacífica de Colombia y la necesidad de otorgarlas en concordancia a las ya existentes en países vecinos del Pacífico como Ecuador y Panamá y países que comparten la problemática como México.

El propósito de este artículo es mostrar la necesidad de diseñar una política pública enfocada en la dinámica actual de la migración irregular con el fin de disminuir o erradicar los obstáculos intervinientes como la inseguridad fronteriza y la vulnerabilidad de los derechos humanos.

A partir de la recolección de datos de diferentes informes oficiales de organismos migratorios, así como de documentos académicos y de prensa e informes de entidades estatales, el presente artículo tiene en cuenta en primera instancia el contexto social y los factores geográficos que hacen de Colombia un país de tránsito y no receptor de inmigrantes. A partir de esta contextualización se podrá ver en la segunda parte las condiciones negativas en Colombia respecto a la seguridad fronteriza, las redes de tráfico de personas y el vacío de presencia estatal frente a la inmigración, lo que se convierte en los principales obstáculos intervinientes de los inmigrantes, vulnerando en la mayoría de los casos su derecho a migrar. En la última parte, en respuesta a la falta de soluciones al problema en Colombia, se contemplan las iniciativas en los países más afectados por la migración de la ruta del Pacífico -Ecuador, Panamá y México-y se proponen varios escenarios para tener en cuenta una posible implementación de 
una política pública en el pacífico colombiano vinculada a las fronteras colomboecuatoriana y colombo-panameña.

\section{Colombia: inmigración de paso}

La inmigración en Colombia no ha tenido mayor representatividad a comparación de los altos niveles de emigración de los colombianos hacia el exterior. En los datos de historia de la Organización Internacional para las Migraciones (OIM), se considera que la primera inmigración en Colombia fue a partir del siglo xvi hasta el siglo XIX con el flujo de españoles en la época colonial. Esta es tal vez la mayor y más contundente inmigración de extranjeros en Colombia, ya que a partir del siglo xx y hasta la actualidad, los flujos de inmigración han sido bajos en comparación a otros países como Brasil o Argentina (Ramírez \& Mendoza, 2013).

En la última década se ha incrementado el ingreso de extranjeros a Colombia, especialmente de países vecinos como Venezuela y Ecuador, y europeos, en su mayoría españoles y alemanes, y consecutivamente ciudadanos estadounidenses (ver figura 1). Sin embargo, tal y como se puede observar en la figura 2, dentro de estas cifras de extranjeros llegando a Colombia no se tiene en cuenta la migración de tránsito en las fronteras terrestres ni un reporte de los inmigrantes irregulares ${ }^{2}$ o del tráfico de personas transfronterizo.

Lo anterior demuestra que el enfoque de las políticas migratorias en Colombia están dirigidas al sector económico -laboral y turístico-, dejando de lado las problemáticas que acarrea la inmigración de tránsito en tanto a la seguridad de las fronteras y el nivel de vulnerabilidad que tienen cierto tipo de inmigrantes al llegar al país. Esta prioridad de las instituciones migratorias de Colombia por visibilizar la "buena" migración, deja de lado la problemática que existe en la región pacífica y las consecuencias que esta trae para la seguridad local, fronteriza y regional tanto de los ciudadanos locales como de los extranjeros.

2 Se entiende como migrante irregular a aquel que carece de condición legal en un país anfitrión o de tránsito al ingresar sin autorización o permanece en el país después de haber vencido su permiso de permanencia (Consejo Internacional de políticas de Derechos Humanos, 2010). 
Figura 1. Extranjeros en Colombia por nacionalidad

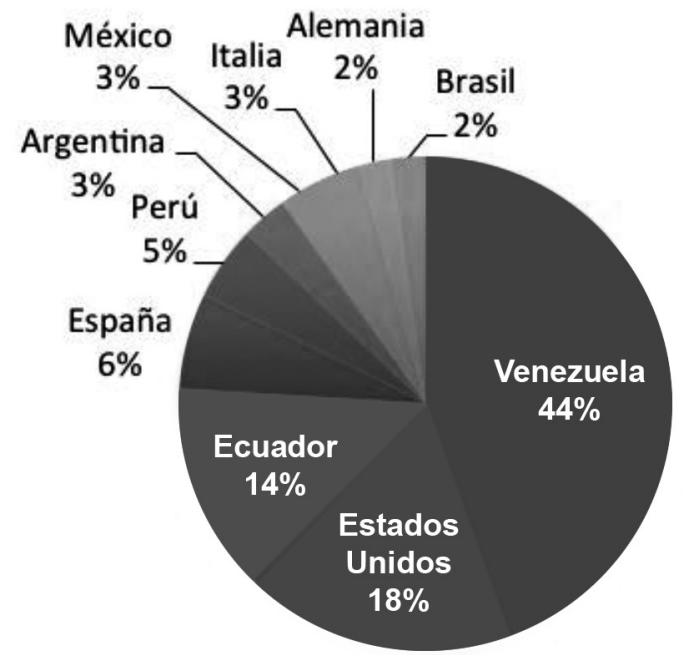

Fuente: Banco Mundial. (2012); Ramírez y Mendoza (2013).

Figura 2. Principales tipos de visa otorgadoas entre 2007 y 2011

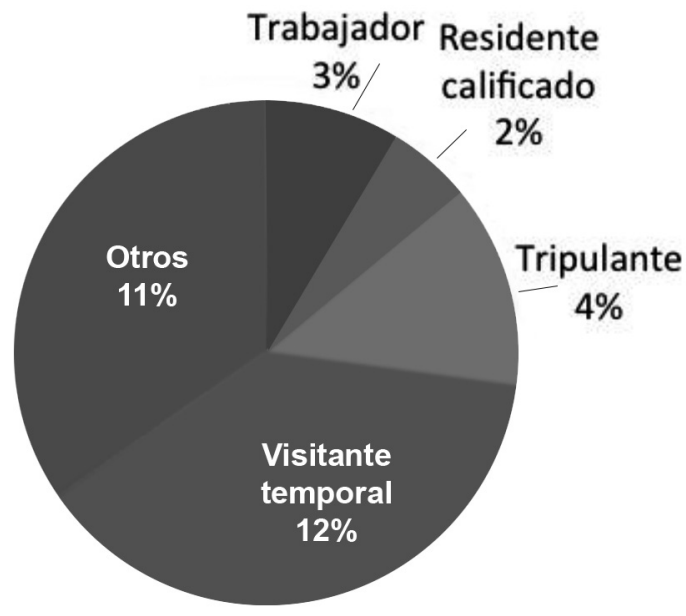

Fuente: Migración Colombia- oIM, 2013.

Estas cifras demuestran que Colombia, a pesar de su crecimiento económico y la mejoría en términos de seguridad, no se posiciona como un país receptor 
de inmigrantes. No obstante, su estratégica posición geográfica lo convierte en el principal destino de tránsito de una nueva ola de inmigración, como se puede observar en la figura 3, provenientes en su mayoría de China, India, Cuba, Bangladesh, Somalia, Kenia, Etiopia y Ecuador y que tienen como objetivo llegar a territorio Norteamericano (ver figura 4).

Figura 3. Nacionalidad de inmigrantes irregulares en Colombia (2012-2014)

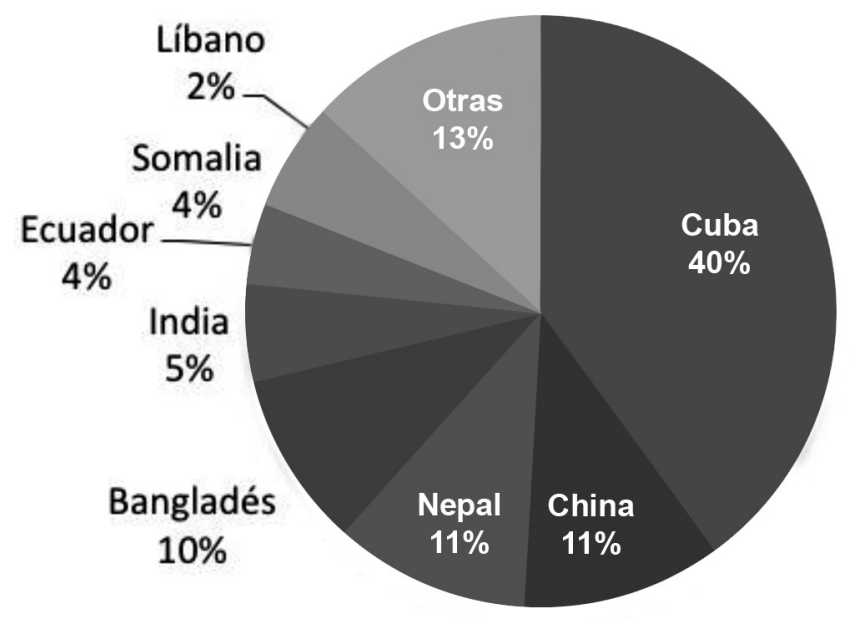

Fuente El Tiempo, 2015.

Figura 4. Mapa de rutas internacionales de inmigrantes irregulares hacia Colombia

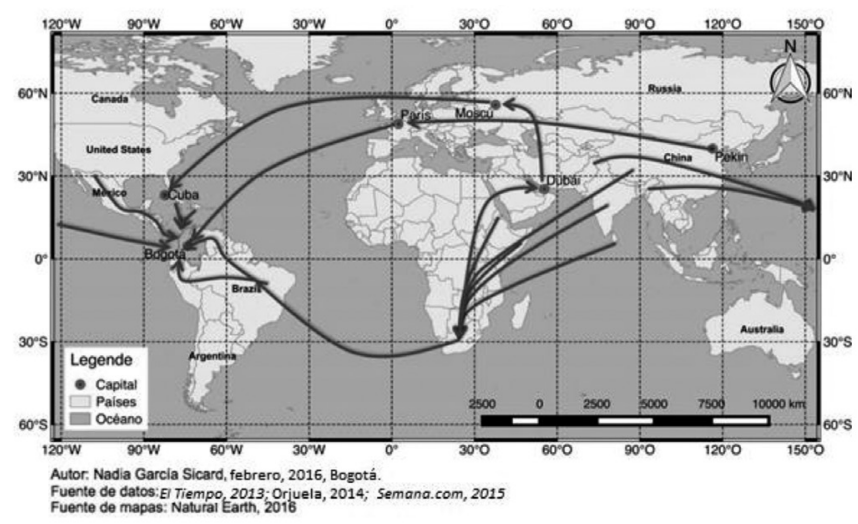


La desunión entre el espacio territorial y el grado de control que sobre él ejerce el Estado, es lo que denominan Ángel Rabasa y Jhon E. Peters "territorios desgobernados", remitiéndose a lo que atañe al control del Estado, más allá de dominio de su territorio y población sino de la efectividad y funcionamiento de sus instituciones. El modelo propuesto por los autores acerca del grado de ingobernabilidad del territorio se establece en cuatro indicadores: 1) deficiente penetración de las instituciones estatales en la sociedad; 2) deficiente gestión del monopolio del uso de la fuerza por parte del Estado; 3) deficiente control de los flujos transfronterizos; y 4) la vulnerabilidad a interferencias externas (Molano-Rojas \& Salazar, 2016, pág. 23).

Basado en este modelo y lo que respecta al problema propuesto en este artículo, el deficiente control de los flujos migratorios es tanto consecuencia de los otros 3 factores como también impulsador de los mismos. Específicamente, las fronteras entre Ecuador y Panamá, al ser desgobernadas, carecen de control y se han convertido en límites sensibles a la migración irregular; son propensas a ser las mejores rutas migratorias por donde se propagan y generan los problemas de seguridad y vulnerabilidad. Así, los niveles de corrupción, la presencia de grupos armados irregulares, el crimen organizado y el tráfico de personas, drogas y armas, son el resultado de la ingobernabilidad de las fronteras y el aumento de migración irregular por las mismas.

Entre tanto, las rutas migratorias del Pacífico han sido aprovechadas por los traficantes de migrantes, quienes han organizado una infraestructura de movilidad y resguardo junto con redes de intercambio de personas, drogas y armas, lo que ha aumentado los niveles de inseguridad en las zonas fronterizas ${ }^{3}$. El crecimiento y fortalecimiento de estas redes criminales y las "facilidades" de paso irregular migratorio se presenta ante la dificultad de las agencias de seguridad, como la policía o el ejército, de penetrar estas zonas ambientalmente densas, en particular, aquellas ubicadas en el tapón del Darién entre la frontera colombo-panameña, y las salidas al océano Pacífico y al mar Caribe (UNODC \& Colombia, 2013) (ver figura 5).

Las fronteras desgobernadas, junto al problema migratorio irregular, surgen de vulnerabilidades ya presentes en la zona, previas a la inmersión del problema de inmigración. Generalmente, los territorios que no cuentan con el control y presencia del Estado y por ende la presencia de sus instituciones es prácticamente nula; consisten

3

Según la OEA (2010), la llegada a Colombia de forma extracontinental se hace por medio de dos rutas: 1. Del país de origen (principalmente Somalia, Eritrea, Bangladesh, Nepal, Sri Lanka, India y China) hasta Sudáfrica, de ahí toman un avión hasta Brasil y de allí a Perú, Ecuador o Venezuela y posteriormente a Colombia. La segunda ruta parte de Sudáfrica hasta Dubái, de allí en avión se hace escala en Moscú hasta llegar a La Habana. Ya en Cuba toman un vuelo que los lleve a Colombia o Ecuador. Otra de las rutas que ha sido establecida por autoridades colombianas comienza en Beijing, llegan aéreo a París y de allí a Bogotá (MinEducación, 2008). 
de comunidades con condiciones vulnerables a consecuencia de un entorno social, cultural o demográfico, influenciado por grupos y actividades irregulares que pueden tener más control del territorio y su población que el mismo Estado (Molano-Rojas y Salazar, 2016, pág. 29)

Figura 5. Mapa de rutas internas del Pacífico colombiano

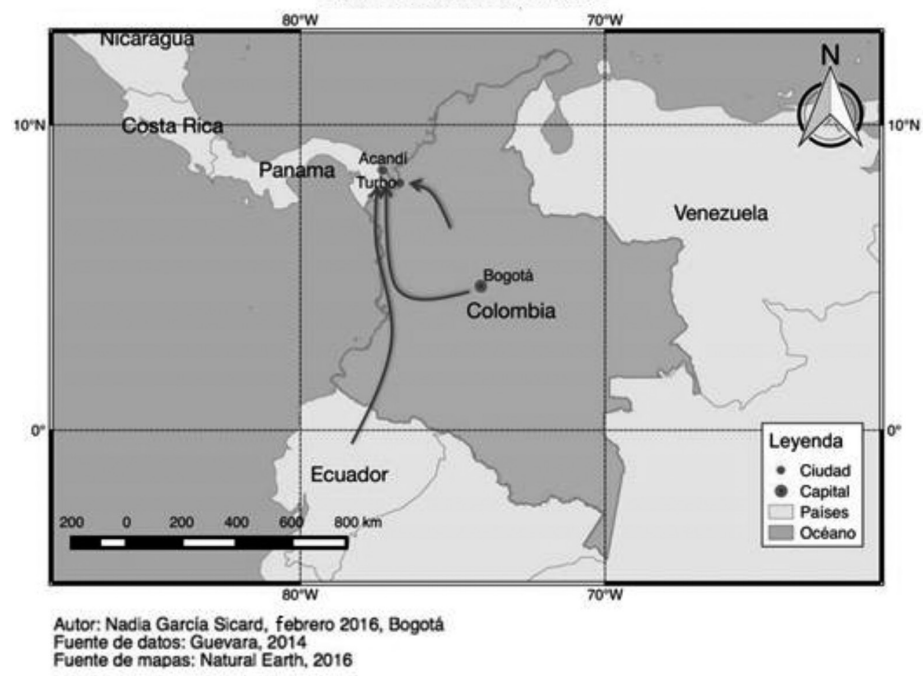

Como "territorio desgobernado", el tapón del Darién se caracteriza por su complejidad de acceso debido a sus condiciones geográficas y de seguridad dada la presencia de grupos al margen de la ley. Estas características crean un doble problema al ser asequibles al tráfico de migrantes que traspasan la frontera hacia Panamá, donde primero incentivan los grupos y actos delictivos locales y segundo, no existen condiciones para proteger al inmigrante. De esta manera, la inseguridad para el inmigrante en esta región se intensifica no solo por la mera presencia de los grupos armados ilegales, sino porque ellos mismos hacen parte del tráfico ilícito de migrantes hacia Panamá y Centroamérica (UNODC y Colombia, 2013).

A pesar de la falta de control del Estado en las zonas de alta movilidad de migración, este fenómeno se ha incrementado notablemente en los últimos años. El reporte entre 2012 y 2014 de Migración Colombia ${ }^{4}$ estima que aproximadamente

4 Dependencia del Ministerio de Relaciones Exteriores, encargada del control migratorio en Colombia. 
1.256 inmigrantes han entrado a territorio colombiano con intenciones de tránsito hacia Estados Unidos (Migración Colombia, 2014).

Las características físicas de Colombia y los factores que integran las fronteras "no gobernadas" facilitan la porosidad de las mismas, convirtiéndose en territorios de tránsito de inmigración irregular. Las consecuencias que Colombia se convierta en un país tránsito de inmigración irregular es el aumento de la inseguridad fronteriza y local en donde se interconectan varios problemas como: zonas en conflicto, pobreza, desatención institucional, altos niveles de corrupción y fortalecidas redes de tráfico.

Figura 6. Los obstáculos intervinientes: la travesía de la ruta del Pacífico

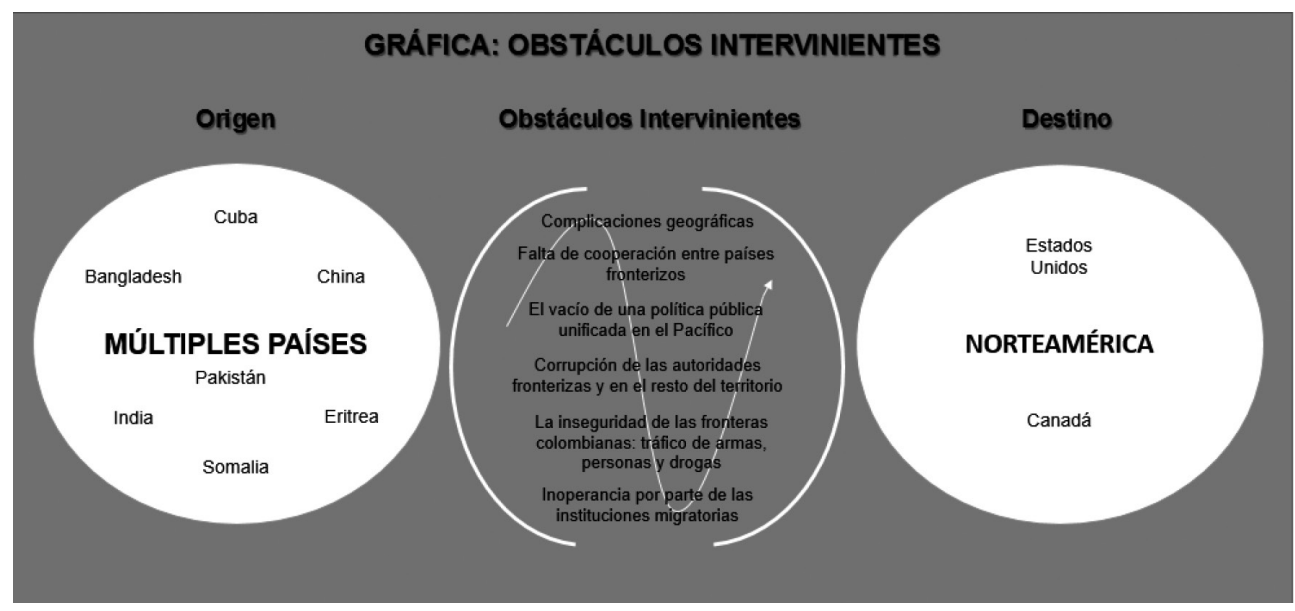

Fuente: elaboración propia del autor basada en la Teoría de las Migraciones de Lee (1966).

Tal y como se nombró anteriormente, el fenómeno migratorio ha sido ampliamente estudiado particularmente desde la Teoría Migratoria de Everet S. Lee (1966), la cual enmarca los push factors o motivos que llevan a las personas a emigrar, bien sean por razones socioeconómicas, políticas o medioambientales; y así mismo, los pull factors, factores que estimulan la migración en un país particular en donde generalmente la estabilidad económica y política son las principales razones que tiene un país receptor de inmigrantes.

Aunque los estudios migratorios son amplios a partir de la propuesta teórica de Lee se han dejado de lado los obstáculos intervinientes, factores clave que le permiten al migrante llegar a su objetivo final pero que dentro de este proceso puede encontrar un gran número de vulneraciones, limitantes y complicaciones que en muchos casos le dificultan llegar al país destino. Teniendo en cuenta los obstáculos intervinientes, 
esta sección se enfocará en describir las principales problemáticas con las que se encuentran los inmigrantes al atravesar las fronteras colombianas para llegar a Panamá y seguir su trayecto rumbo a Estados Unidos.

Para atravesar el país se usan, al igual que en México, los "coyotes" (transportadores de inmigrantes) que en su mayoría son nacionales colombianos, ecuatorianos y panameños. Los "coyotes" tienen como primer destino Ecuador para movilizar a los migrantes hacia Panamá y posteriormente atravesar los países de Centroamérica hasta llegar a Norteamérica. En el caso colombiano, los "coyotes" no son únicamente personas que se dedican al tráfico de personas, sino que pueden ser integrantes de diferentes Bandas Criminales Emergentes (Bacrim), frentes de la guerrilla de las FARC y agentes estatales (UNODC y Colombia, 2013; Gutierrez. 2016).

Cualquiera que sea la modalidad de traslado de país a país, el inmigrante debe enfrentarse a varios obstáculos que los mismos traficantes les interponen. El primero es el factor monetario. Los altos costos del viaje, desde su lugar de origen, deben sumarse a los gastos de "trámites" de paso fronterizo, estadía y transporte que organiza el "coyote"; además, estos pagos deben ser dados en dólares y pesos. El costo aproximado del recorrido hasta Estados Unidos puede estar entre USD 8.000 y USD 30.000 y en muchos casos a los inmigrantes, al no poder pagar las altas sumas de dinero, se les cobra el trabajo y los trámites del "coyote" con prostitución, trabajos forzados o tráfico de armas o droga (Orjuela, 2014).

Un segundo obstáculo es la falta de visas y documentos legales para el tránsito hacia Norteamérica. Este problema suelen resolverlo los "coyotes" con la compraventa de documentos falsos y oficiales que se da en mayor medida con la venta de pasaportes falsos de nacionalidades "menos problemáticas" como la peruana. Por otra parte, la compra de documentos oficiales se hace particularmente con las solicitudes de asilo, los cuales son vendidos por solicitantes de asilo -particularmente africanos. Los "coyotes" se convierten en sus compradores potenciales para posteriormente revenderlos a las redes de tráfico (OEA, 2010). ${ }^{5}$

Una nueva modalidad de falsificación de documentos es por medio de las visas de trabajo, lo que permite la entrada de extranjeros al país por vía aérea con una visa supuestamente legal. Luego de permanecer uno o dos días en la capital, se dirigen por tierra hacia el noroccidente del país para seguir su ruta (El Tiempo, 2013).

El tercer obstáculo al que se enfrentan los inmigrantes es el arriesgado recorrido inter-fronterizo, teniendo en cuenta las extensiones geográficas, las dificultades de movilidad y las redes ilegales de tráfico de personas. El desplazamiento desde Ecuador

5 Colombia, como país firmante de la Convención sobre los Refugiados de 1951, debe recibir a cualquier persona que solicite protección internacional. Por ejemplo, para 2009 el país recibió 334 solicitudes de asilo de países fuera del continente americano, principalmente de Somalia (oEA, 2010). 
atravesando Colombia hasta su frontera con Panamá se hace generalmente por tierra, usando buses públicos. En este trayecto se han encontrado en su mayoría extranjeros chinos, cubanos, paquistaníes y bangladesíes. A la llegada al tapón del Darién, en las ciudades de Turbo (Antioquia) y Juradó (Chocó), los "coyotes" embarcan a los inmigrantes en lanchas que pueden ir cargadas de droga. El mayor riesgo de esta modalidad por vía marítima se corre cuando los traficantes detectan controles de la policía de fronteras, botando al mar a los extranjeros y dejándolos ahogar (Guevara, 2014 y El País, 2015).

Por otra parte, además de los inconvenientes descritos anteriormente, los inmigrantes irregulares se enfrentan a las respuestas jurídicas y legales propuestas por el Gobierno. La puesta en marcha de políticas de control y la seguridad fronteriza en conjunto con la policía y la armada nacional, sumado a las detenciones y deportaciones, criminalizan al inmigrante dejándolo en una situación de vulnerabilidad aún mayor que de la que proviene de su país de origen (Semana.com, 2015).

Los informes de Migración Colombia muestran que el ingreso de extranjeros de forma irregular ha aumentado (ver figura 3), así como su detención y deportación. Si este accionar de Migración Colombia se analiza bajo la premisa de la seguridad nacional y de las fronteras, se podría establecer que se hace un buen trabajo al encarcelar y deportar "ilegales"6. Sin embargo, no se está teniendo en cuenta que, más que inmigrantes irregulares, son personas migrantes que tienen derechos contemplados por el Derecho Internacional Humanitario, la Convención para los Refugiados y las estipulaciones en cuanto a migrantes por parte de la oIM, junto con las políticas migratorias colombianas (UNODC y Colombia, 2013; El Tiempo, 2013).

De esta manera se puede ver que los obstáculos intervinientes a los que se enfrenta el inmigrante pueden ser de tipo económico, administrativo, de seguridad y logístico. Estos son exacerbados ante el vacío de institucionalidad y de accionar por parte del Gobierno. Organismos como Migración Colombia y su articulación con cuerpos oficiales de seguridad se encargan de un mero control fronterizo que, más allá de promover un control migratorio óptimo, ha criminalizado a los inmigrantes, aumentando con esto su vulnerabilidad y sumándole un obstáculo más en medio de su recorrido hacia un "mejor lugar".

\footnotetext{
6 La relación entre los movimientos migratorios y la seguridad nacional se incrementó a nivel mundial a partir de los ataques del 9/11 en Estados Unidos. Denominar “ilegal” al inmigrante conlleva a una tipificación negativa de la persona que deja su lugar de origen y se dirige a otro. Teniendo en cuenta la (de)-construcción y los negativos estereotipos del migrante, el fenómeno migratorio actual se relaciona con seguridad nacional, el conflicto y el desorden a una escala global (Miller y Castle, 2003, S. 283).
} 
Teniendo en cuenta las problemáticas anteriormente mencionadas, es de suma importancia la implementación de una política pública enfocada principalmente a los inmigrantes irregulares, quienes a pesar de no aportarle los mismos beneficios económicos como los migrantes de trabajo o los turistas, merecen también ser tratados bajo la regulación de sus derechos como migrantes. El fin de la puesta en marcha de una política pública para los inmigrantes irregulares es disminuir los obstáculos intervinientes que se les presentan en el tránsito por Colombia.

Figura 7. Número de inmigrantes irregulares descubiertos en Colombia

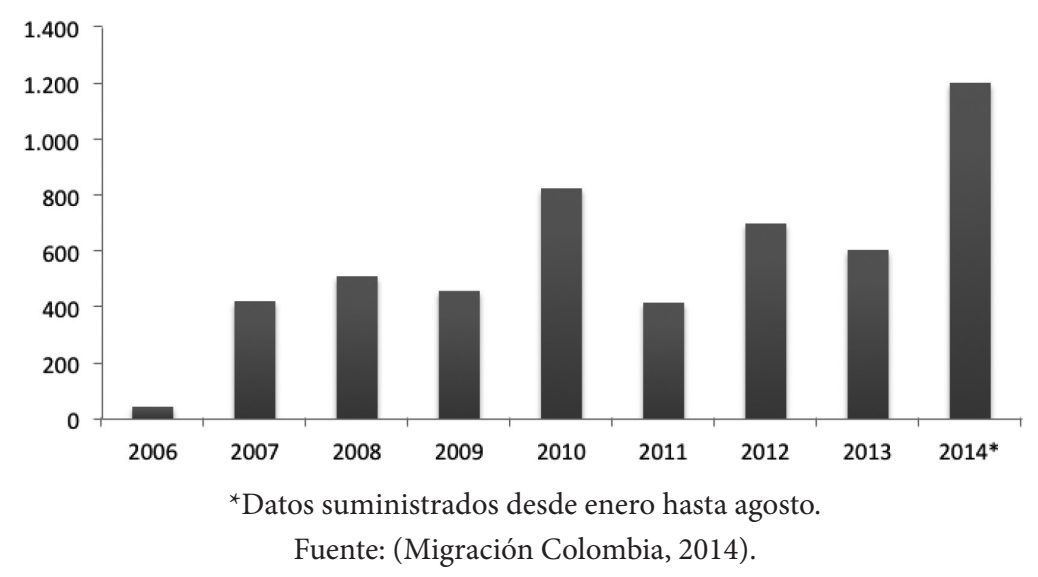

\section{Aportes de las políticas públicas de países tránsito de la ruta del Pacífico}

El movimiento migratorio por las rutas del Pacífico ha tenido diferentes niveles de incidencia y afectación en las zonas de tránsito de inmigrantes. De acuerdo a esto, los gobiernos nacionales, locales y en conjunto con organizaciones no gubernamentales, se han dado a la tarea de implementar políticas públicas que den respuesta a las necesidades tanto de los inmigrantes como de la comunidad local. En este caso, Ecuador, Panamá y México comparten las mismas problemáticas que Colombia. La diferencia entre estos países es el nivel de flujo migratorio para la implementación de una adecuada política pública. El previo conocimiento y el estudio de este accionar político puede aportarle un panorama de creación e implementación de soluciones a la migración de tránsito en Colombia. 


\section{Ecuador}

Ecuador se caracteriza por ser un país emisor y receptor de migrantes. Así como desde la década de los años ochenta una gran cantidad de ecuatorianos emigraron principalmente hacia Estados Unidos, España y países vecinos, también se ha convertido en país tránsito por los inmigrantes de paso que se dirigen a Norteamérica. Sumado a su caracterización de país emigrante y de tránsito, es uno de los países de Suramérica que más acoge refugiados colombianos. Esta distinción ha obligado al Gobierno ecuatoriano a implementar políticas públicas que respondan a los dos fenómenos.

Como primera medida, en Ecuador se da la mención de "movilidad humana" al derecho humano de migrar, sin distinción de formas de migración ni identificaciones como "ilegal" por su condición migratoria (Tipanluisa, 2011, p. 9).

El concepto de "movilidad humana" se ha convertido en el eje central de la política migratoria en Ecuador, en donde a partir del reconocimiento "del derecho de migrar, la persona migrante se convierte en un sujeto de derechos, un actor transnacional en el desarrollo humano, y un sujeto político con capacidad transformadora del espacio migratorio en el que se envuelve" (Tipanluisa, 2011, p. 10).

Esta percepción de la movilidad humana inspiró a la Constitución Política del 2008, al ratificar el principio de la ciudadanía universal que da vía libre a la movilidad por su territorio a todas las personas sin importar su nacionalidad. En 2010, Ecuador replanteó su política de cero visas, estipulando que:

"Las políticas públicas en materia de movilidad humana muestran un modelo de integración social desde una perspectiva de respeto a los derechos humanos. Actualmente los ciudadanos extranjeros no requieren de visa para ingresar al Ecuador por el lapso de 90 días con fines turísticos; excepto los ciudadanos de la República Popular China, Afganistán, Bangladesh, Eritrea, Etiopía, Kenia, Nepal, Nigeria, Pakistán y Somalia, que si requieren de visado"7 (Ministerio del InteriorEcuador, 2014).

Ecuador asume la migración como una responsabilidad del Estado con un carácter transnacional integrando modelos de desarrollo económico, social y político, por lo cual articula la política de migración como una política de Estado basada en el respeto y ejercicio de los derechos humanos, económicos, sociales y culturales por

7 A 2016 existen vacíos e inoperancias frente a la integración y regularidad especialmente de inmigrantes y refugiados provenientes de Haití y Cuba. Por su parte, los inmigrantes que mayores facilidades han tenido gracias a estas políticas han sido los colombianos y peruanos (Alarcón, 2012). 
medio de los procesos de desarrollo e interculturalidad de las personas migrantes y su entorno. La inmersión de la política migratoria como política de Estado enriquece su desarrollo y función al integrar tanto al migrante como al población local en los espacios de construcción de una ciudadanía universal (SENPLADES, 2009).

Bajo este concepto, la política migratoria ecuatoriana integra el fenómeno de la migración estipulada tanto para el emigrante ecuatoriano que reside fuera del país como para el inmigrante o refugiado. En lo que interesa para los aportes de políticas públicas en cuanto a los inmigrantes extranjeros, Ecuador localiza sus políticas en tres áreas principales: 1) la dimensión jurídica en la que regulariza y reconoce a los inmigrantes sin importar su condición o status migratorio. 2) La dimensión social en el ámbito laboral que estimula a la creación de condiciones laborales equitativas para la población inmigrante. Dentro de esta misma dimensión se encuentra el acceso a servicios públicos en especial al acceso a la salud y educación para inmigrantes y refugiados. 3) La dimensión cultural donde se impulsan actividades de integración e intercambio cultural entre extranjeros y la población local con apoyo de organizaciones sociales (Senplades, 2009)

Los principales aportes del modelo migratorio ecuatoriano se desprenden de la imagen de ciudadanía mundial y la no categorización del migrante como irregular. Estos dos aportes ayudan a descriminalizar los procesos de desplazamiento y movilidad, rescatando el deber de los Estados de proteger a todas las personas sea cual fuere su origen, destino y razón de migrar. Además, visibiliza a todas las personas que migran, sin focalizarse en una migración positiva (como el turismo) o en una negativa (como los inmigrantes irregulares), enmarcándolas bajo los mismos derechos humanos. Estas prácticas ayudan a posibilitar el diseño y la aplicación de la política pública de migraciones desde un ámbito transnacional y, como lo proyecta Ecuador, hasta el ámbito mundial.

\section{Panamá}

Otro de los países en los que se puede fijar la atención en materia de políticas públicas sobre migración es Panamá, que cumple con la misma dinámica colombiana de país de tránsito pero al mismo tiempo es uno de los países con mayor solicitud de refugio.

Este país cuenta con una figura denominada Protección Temporal Humanitario (Ртн), que es directamente comparable con la condición de refugiado. En esta última, el beneficiado no cuenta con ninguna restricción de su movimiento en el territorio nacional, en contraste con los beneficiados con la medida del PTH. Tal restricción al desplazamiento interno les condiciona la oportunidad de adquirir derechos básicos e 
integración social como los procesos educativos o de alternativas laborales (Consejo Noruego para Refugiados, 2015).

Así mismo, Panamá, en su política migratoria, le da un mayor enfoque a las necesidades de los refugiados y el proceso de regulación dentro del país. Con este fin, su política migratoria es diseñada gracias a los aportes extraidos de la cooperación con organizaciones y entidades tales como la organización Asylum Access Latin América, que busca coordinar operaciones referentes a la solicitud de refugio y asilo entre los países miembros (Asylum Access, 2015); además del Ministerio de Gobierno a través de Onpar, el Servicio Nacional de Migración, la Policía Nacional, la Cruz Roja Nacional, el Tribunal Electoral, el Ministerio de Relaciones Exteriores y el Consulado de Colombia en Panamá (Consejo Noruego para Refugiados, 2015).

El diseño de la política migratoria en Panamá a partir de la coordinación y la cooperación entre el Gobierno de Panamá y diversas entidades públicas y privadas, nacionales e internacionales, ayuda a una aplicabilidad más efectiva de acuerdo a enseñanzas y aportes de realidades y situaciones ya tratadas, investigadas $y$ aplicadas en otras regiones.

\section{México}

México es el país más afectado por la inmigración irregular ya que su frontera congrega a todas las personas provenientes de muchos países que desean pasar a Estados Unidos. En tanto que las consecuencias se dan de lado y lado de la frontera, México da apertura a la iniciativa Mérida, en cooperación con EE.UU. Esta se especializa específicamente en combatir el crimen organizado y se compone de tres pilares: a) medidas contra el narcotráfico, contraterrorismo y seguridad fronteriza; b) seguridad pública y Estado de derecho y c) fortalecimiento de las instituciones y la ley. Comprende esfuerzos para promover el intercambio de información, mayor equipamiento, tecnología, capacitación y transporte aéreo (Ramos, 2012, pp. 9-12).

La iniciativa Mérida se ve complementada también con programas que promueven la protección del migrante en su paso por el país. Una de ellas son los grupos Beta que tienen el objetivo de proteger y defender los Derechos Humanos de los migrantes, sin distinción de su nacionalidad o situación migratoria. Estos grupos brindan auxilio y salvaguarda de los migrantes ante situaciones de riesgo o intentos de abuso por parte del crimen organizado, de las autoridades y particulares, y les ofrece información y orientación sobre los riesgos del camino, con la finalidad de persuadir a los migrantes para regresar a sus lugares de origen (Lothar y Lopez, 2011).

Así mismo el trabajo que la Asociación Civil FM4 Paso Libre despliega en la Zona Metropolitana de Guadalajara cuenta con un Centro de Atención a Migrantes (CAM). 
A cada migrante que pasa por el CAM se le hace una breve entrevista para recolectar datos esenciales los cuales sirven para hacer un retrato de todo lo que sucede en la Zona Metropolitana con las personas en tránsito. Con estos datos se logra dar a la población una correcta y verdadera información acerca de los inmigrantes. Así, se intenta que la opinión pública deje de criminalizar al inmigrante y al mismo tiempo hace un llamado para solidarizarse con los inmigrantes más vulnerables (mujeres y niños), convirtiendo de esta manera a la sociedad civil en un agente proactivo (Semanario, 2014).

A pesar de la participación proactiva de organizaciones no gubernamentales y otras iniciativas de los Gobiernos locales, el problema de la seguridad fronteriza ente México y Estados Unidos, deja de lado la vulnerabilidad de los inmigrantes, creando la necesidad de implementar políticas más duras, como es el caso de la Ley SB1070, que "le permite a los agentes de la policía estatal y municipal revisar la condición migratoria de las personas, con base solo en la "sospecha razonable" de que se encuentran indocumentados en el país, así como arrestar a alguien sin orden judicial si el agente dispone de una 'causa probable' para creer que tiene un estatus 'ilegal' (Ramos, 2012). Esta cooperación interestatal limita sus acciones ante la problemática migratoria en términos de derechos humanos y victimización y, por el contrario, se dedica a fortalecer el enfoque post-9/11 sobre la relación migración-inseguridad.

\section{Problema conjunto en la cooperación compartida con Asia-Pacífico}

Sumado a los aportes que las políticas migratorias de Ecuador, Panamá y México para el planteamiento de una política pública que responda a las necesidades y problemáticas de la región pacifica colombiana, es necesario tener en cuenta otros mecanismos para un buen quehacer de políticas duraderas y efectivas. Para ello es necesario contar con la articulación de un trabajo en conjunto con organismos y entidades que brinden y apoyen los medios de financiación, sostenibilidad, regulación institucional y seguimientos de control del proyecto.

Entre tanto, la Corte Constitucional reconoce la problemática de la inefectividad de los planes y decisiones políticas respecto a los desplazados e inmigrantes dado el bajo compromiso de las entidades territoriales para atender a la población. Sin embargo, distingue dos principales cuestionamientos: a) ¿Por qué la entidad territorial carece de presupuesto para atender el problema social con los desplazados? b) ¿Por qué la entidad territorial no ha puesto el tema en su agenda de prioridades? (Consejo Noruego para Refugiados, 2010).

Estos limitantes pueden ser superados a través de una óptima cooperación. Según Alexander Betts (2009), la cooperación internacional es necesaria para superar 
las más negativas consecuencias de la migración, en especial la migración forzada e irregular. La recepción de un alto flujo de inmigrantes, la protección para los refugiados o desplazados y las emergencias humanitarias requieren generalmente de una alta capacidad económica y óptima preparación logística y legislativa que no tienden a tenerlas en pleno un solo país. Por esto, el abordar las causas fundamentales del problema, la toma de decisiones correspondiente a la protección y las soluciones durables se basan en la colaboración y coordinación entre dos Estados o más (Betts, 2009, p. 80).

Los proyectos de cooperación pueden ser extendidos bajo la apertura de las relaciones intra y extraregionales, integrando fundaciones privadas internacionales especialmente de países del Asia Pacífico como Corea del Sur, Japón y China, que en la última década han fortalecido considerablemente sus redes de cooperación con Latinoamérica, dado sus intereses económicos en la región, a través de importantes aportes al desarrollo industrial, en las áreas de la educación y lo empresarial (Barbosa, Posada y Serrano, 2011, pág. 72).

Por medio de la diplomacia empresarial, política y temática ${ }^{8}$ estos países del Asia Pacífico pueden ofrecer un importante apoyo, especialmente logístico y financiero, para la aplicación de una política de Gobierno que más allá del soporte al inmigrante, ayude a la seguridad fronteriza y de los puertos del Pacífico. Esto aportaría tanto al fortalecimiento de la seguridad en la región -lo que llamaría aún más la atención de la inversión asiática-, como al mejoramiento de la situación del inmigrante. Así se generará un beneficio recíproco y se articulará la cooperación económica con el desarrollo social.

\section{Consideraciones para la política pública sobre migración internacional en Colombia}

Tal y como es desarrollado por Aristizábal y Villegas (2012), la política pública debe responder a un problema social, que en este caso es la migración irregular de extranjeros en territorio colombiano y extendida a lo largo del Pacífico. Es claro que la política busca dar una solución o disminución de las problemáticas que aqueja la inmigración irregular, especialmente para reducir la vulnerabilidad del inmigrante y

8 Sobre diplomacia económica y comercial, cooperativa, política y temática entre Colombia, América Latina y Asía Pacífico, ver (Barbosa, Posada y Serrano, 2011, págs. 62-93) 
brindarle unas garantías de protección temporal, lo que se reflejará en el mejoramiento de la seguridad fronteriza.

Consecuente a que las migraciones (independiente de su naturaleza, voluntaria/ involuntaria) se convierten en objetivos políticos, la aplicación de una apropiada política migratoria llega a ser una cuestión altamente cuestionable que depende de varios factores: el perfil de los migrantes, las necesidades de la población migrante y local, la capacidad de las instituciones para accionar, así como el nivel de vulnerabilidad de los migrantes y el impacto que esa migración está generando en el lugar de llegada (Collinson, 2011, pág. 318). En este sentido, a pesar que los inmigrantes en Colombia se generalizan dentro del formalismo institucional (en este caso Migración Colombia), tienden a ser objetivo político cuando en alguno de los factores anteriormente mencionados tienen un impacto y una vulnerabilidad relevante tal y como se evidenció en lo referente a los obstáculos intervinientes.

Por otra parte, la política pública para la migración irregular en Colombia, como país de tránsito, deberá estar planteada desde dos frentes. El primero, guiado a políticas internas, tomadas desde los Gobiernos locales, regionales y el Gobierno nacional y aplicadas directamente en territorio colombiano, en especial en las zonas de alta movilidad inter-fronteriza de migrantes tales como las fronteras colomboecuatoriana y colombo-panameña. Segundo, a nivel externo, en donde se logre la cooperación con países que compartan esta problemática, especialmente con Ecuador y Panamá, integrando países del Asia Pacífico y México.

\section{Enfoque interno}

La iniciativa para la creación de una política pública de migraciones concentrada en el nuevo tipo de migrante que ingresa a Colombia (refugiado, irregular o en tránsito), debe partir de la responsabilidad directa que tiene el Estado sobre las causas y consecuencias de este fenómeno. En este caso, Colombia como país receptor debe asumir la responsabilidad de garantizarle a los inmigrantes el goce de sus derechos fundamentales creando espacios y generando condiciones que les permita tener unas adecuadas condiciones de vida, bien sea mientras su paso de tránsito por territorio colombiano o como inmigrante asentado.

Así mismo, se debe diferenciar entre el migrante que por los obstáculos intervinientes se ve obligado a quedarse o transitar de manera irregular en Colombia, y los migrantes regulares bien sean turistas, estudiantes o de trabajo. Ante estos dos tipos de migración, es necesaria la implementación de una reforma migratoria que integre los mecanismos para regularizar a los inmigrantes y controlar el acceso 
al territorio de los mismos. En este punto se puede tener en cuenta el carácter de regularización e integración propuesta en la política migratoria de Ecuador en tanto que, además de regularizar a los inmigrantes, les permite integrarse a la sociedad por medio de posibilidades laborales y educativas.

En el caso de los inmigrantes irregulares, se debe evitar la criminalización inmediata de la persona al abrirles un proceso judicial, llevarlos a prisión y seguidamente deportarlos. Por el contrario, se contemplaría una condición de permiso temporal dentro de un plazo y lugar definido. Un ejemplo claro al respecto son los beneficios que recibieron algunas familias desplazadas por la violencia en la década de los años a partir de la figura del Estatuto Humanitario Provisional de Protección concentradas en las provincias fronterizas con Panamá, el Darién y Guna Yala. A pesar de la figura creada de protección temporal, estas familias no poseen todos los derechos y beneficios que tiene la figura del refugiado y por esta razón tiene limitaciones de movimiento en el resto de regiones panameñas (Consejo Noruego para Refugiados, 2015)

Sin dejar de lado la relación de la problemática de la inmigración con la seguridad interna, es preciso reforzar los requerimientos de visas y documentos en los pasos fronterizos, además de puertos y aeropuertos. Actualmente, según comunicados oficiales de la Cancillería de Colombia (2014), se estaría estudiando la posibilidad de exigir visa de tránsito a los ciudadanos de los países que han presentado mayor número de casos de inmigración irregular o de solicitudes de refugio dentro del país sin las condiciones mínimas para solicitarlo. Ghana, Somalia, Cuba y Bangladesh son los países a cuyos ciudadanos se estudiaría solicitar visa de tránsito.

\section{Enfoque externo: extensión de la política pública con países limítrofes}

A partir de una propuesta de plan de acción a nivel interno del país, es preciso contemplar la cooperación junto con otros Estados en materia migratoria, particularmente con la propuesta de política migratoria transnacional y mundial de Ecuador y las posibilidades de cooperación con los países de Asia Pacífico. La ausencia de una cooperación eficaz entre los países afectados, especialmente los que comparten frontera, limita el accionar y los resultados de una política pública a nivel interno o sectorial, cuando el problema se extiende y se comparte con otros países.

La toma de decisiones multilateral por parte de Colombia, Ecuador, Panamá y México, respecto a la inmigración de tránsito por la ruta del Pacífico reduciría los problemas de seguridad en donde se integra el contrabando de armas y droga junto 
con el tráfico de personas. Frente a este tema, Colombia ha liderado la iniciativa de conformar la Red Iberoamericana de Autoridades Migratorias para articular el intercambio de información de seguridad (El Tiempo, 2015). A pesar de la proyección del Gobierno nacional por fortalecer la cooperación internacional con el fin de articular y promover la Política Integral Migratoria en la frontera colombo-ecuatoriana, esta tiene hasta el momento unos fines primordialmente económicos, dejando de lado la necesidad de llevar esta política a un ámbito de seguridad fronteriza y protección al inmigrante. En este sentido, la política migratoria ecuatoriana, a pesar de su accionar a nivel interno sobre regulación y seguimiento al inmigrante, no ha logrado tener mayores alcances en la frontera con Colombia, lo que permea y obstaculiza una aplicación integral transfronteriza.

Así mismo, la medida panameña de Protección Temporal Humanitario (PTH) explicada anteriormente se hace en cooperación entre las instituciones panameñas y el consulado colombiano, lo que ha ayudado a que las responsabilidades que la ley demanda sean compartidas y la aplicación de la misma en sus territorios y jurisdicciones se asimile de la mejor forma para los refugiados (Consejo Noruego para Refugiados, 2015). Este ejemplo de cooperación puede ser extendido en dos frentes: primero, puede incluirse a los extranjeros con mayor nivel de vulnerabilidad (mujeres, niños y personas que han sido víctimas de las redes de tráfico de personas). Segundo, la cooperación se puede extender a organizaciones no gubernamentales, tanto a nivel nacional e internacional, que ayudan a coordinar actividades y procesos por llevar a cabo (Consejo Noruego para Refugiados, 2015). Allí se tendrían que tener en cuenta las organizaciones presentes en Colombia como el Servicio Jesuita a Refugiados Colombia (sJR), La Red Mariposas de Alas Nuevas Construyendo Futuro (presente en Buenaventura) o ACNUR Colombia.

Dentro de las acciones anteriormente nombradas que realiza el Gobierno mexicano para mitigar sus problemas fronterizos, se podrían tomar ideas que aportan para una política pública colombiana: a) un diseño estratégico, integral y trasversal que promueva políticas reactivas y de prevención; b) un mayor conocimiento de territorio y del perfil del inmigrante; c) el fortalecimiento de un grupo de élite militar, con conocimiento especializado en crimen organizado; d) el robustecimiento de capacidades del resto de los actores, entre ellos organizaciones no gubernamentales e instituciones del Estado; e) el fortalecimiento de los mecanismos anticorrupción y f) contemplar una toma de decisiones multilateral por medio de acuerdos de cooperación (Ramos, 2012).

Con el objetivo de implementar una política pública para los inmigrantes irregulares, se debe tener en cuenta -como prioridad- la protección a los derechos humanos por encima de su condición irregular. Así mismo, luchar a favor de los derechos humanos de los migrantes es reducir el impacto de la trata de personas o como es llamada por 
(Quijano, 2006) la "economía criminal", en tanto los traficantes toman a las personas como mercancía por la cual recibirán una suma de dinero, sin importar la vulneración y violación de sus derechos. Para dar frente a la vulneración de Derechos Humanos, se debe ir más allá de la propuesta ecuatoriana al dar acceso laboral, de educación y salud; además, se debe plantear el acceso a vivienda o sitios de acogida ya que muchas personas en la frontera colombo-ecuatoriana son expuestas a la trata de personas, fraudes y extorsión al no contar con un lugar de acogida y se ven obligados a vivir en zonas aisladas, lo que les imposibilita acceder a las oficinas migratorias ecuatorianas (EFE, 2012).

La implementación de una política pública conjunta aportaría beneficios para las dos partes, tanto a la seguridad y control migratorio de los países afectados como al mejoramiento de las condiciones de los inmigrantes al llegar o transitar por los países. Sin embargo, la toma de decisiones para llevar a cabo una política pública conjunta requiere no solo de la necesidad ante un problema compartido o la disposición de los Gobiernos por tomar acciones, sino también se debe contemplar las capacidades económicas, logísticas y organizacionales para efectuar de la mejor manera la política pública. Además de esto, el impacto que ha tenido la migración a nivel mundial en la última década y particularmente en esta región en cuanto a desestabilidad social e inseguridad influye y afecta las decisiones estatales, por lo que se considera pertinente una toma de decisiones a través de la cooperación conjunta con países que se interesen en ver a esta región en las mejores condiciones.

\section{Conclusiones}

Los cambios en las dinámicas sociales, económicas y de movilidad dentro del marco de la globalización han generado nuevas razones e impulsos para fomentar la migración a nivel mundial. Bien sean países "promesa" que ofrecen alicientes que llaman la atención de las personas en busca de mejores oportunidades y una mejor calidad de vida, o los países con problemáticas económicas y sociales, que se ven afectados e influenciados por las nuevas olas migratorias. En este sentido, Colombia, a pesar de ser un país emigrante por excelencia y con una seria problemática de desplazamiento forzado interno, se concibe actualmente como uno de los países insignia para el movimiento migratorio de tránsito sur-norte.

Tal y como se evidenció en este artículo, al convertirse Colombia en un país tránsito hacia Norteamérica lo pone en el centro de varias problemáticas a las que no está preparado para enfrentar. Ante este vacío de acciones o soluciones, en este artículo se propuso la necesidad de proyectar, planear e implementar una política 
pública que responda a las necesidades de la población inmigrante de la ruta del Pacífico y los factores de riesgo para la región que el fenómeno atañe: la seguridad fronteriza y el aumento de redes criminales.

Tomando en consideración las políticas de Gobierno y la toma de decisiones frente al flujo migratorio en México, Panamá y Ecuador, se debe tener en cuenta la coordinación entre los demás países afectados por el fenómeno de la migración irregular por el Pacífico, llevando a cabo acciones multilaterales coordinadas y adquiriendo un apoyo económico y logístico por parte de países con mejores capacidades, como los del Asia Pacífico.

De esta manera se puede ver que, ante el aumento de migración irregular en las fronteras colombo-ecuatoriana y colombo-panameña, existen mecanismos que puedan dar respuesta a esta problemática, teniendo en cuenta que más a allá de los beneficios en torno a la seguridad fronteriza, las relaciones diplomáticas y económicas entre los países, lo primordial en este caso es darle visibilidad a un grupo de personas a las que su derecho a migrar les causa una serie de obstáculos que los deja en una situación de alta vulnerabilidad. Esto se convierte en una problemática que no la acarrea únicamente el país receptor, sino también los países tránsito como Colombia, los cuales no tienden a estar preparados en las áreas económicas, legales ni institucionales ante las nuevas dinámicas migratorias. Por esta razón es de vital importancia visibilizar la existencia del fenómeno y la problemática social para así dar paso a la consideración de soluciones que aporten beneficios para todos los actores involucrados.

\section{Referencias bibliografícas}

Alarcón, M. B. (2012). Movilidad Humana e Integración Social en Ecuador de acuerdo al "Plan Nacional para el Buen Vivir 2009-2013". Madrid: Universidad Pontificia Icade Comillas.

AméricaTevé. (2015, 16 de septiembre). Detienen a 17 cubanos con identificaciones falsas en el Pacífico colombiano. From AméricaTevé: http://www. americateve.com/detienen-17-cubanos-identificaciones-falsas-elpacifico-colombiano-n 878728

Aristizábal, J. L., y Villegas, J. A. (2012). Análisis de la Formulación de la Política Pública de Víctimas de Desplazamiento Forzado en la Fase de Retorno en Santiago de Cali: El caso del Plan Integral Único (PIU) 2009-2010. Cali: Universidad del Valle. 
Asylum Access. (2015). Asylum Access-Panama. From Asylum Access [en línea], disponible en: http://asylumaccess.org/program/panama/

Banco Mundial. (2012). Índice de datos- Colombia. From Banco Mundial [en línea], disponible en: http://datos.bancomundial.org/catalogo-de-datos

Barbosa, F., Posada, E. y Serrano, E. (2011). La Inserción de Colombia en Asia Pacífico. 2020: Colombia en el nuevo océano. Bogotá: Universidad Jorge Tadeo Lozano.

Betts, A. (2009). Forced Migration and Global Politics. Oxford: Wiley-Blackwell.

Collinson, S. (2011). "Forced Migration in International Political Economy. En A. Betts, \& G. Loescher", en Refugees in International Relations (págs. 305323). Oxford: Oxford University Press.

Consejo Internacional de Políticas de Derechos Humanos (2010). Migración Irregular, Tráfico ilícito de migrantes y Derechos Humanos: Hacia la Coherencia. Le Locle: Consejo Internacional de Políticas de Derechos Humanos.

Consejo Noruego para Refugiados. (2010). Los Caminantes Invisibles . Consejo Noruego para Refugiados NRC.

Consejo Noruego para Refugiados. (2015). La llave de la regularización en Panamá. From Consejo Noruego para Refugiados [en línea], disponible en: http:// www.nrc.org.co/index.php/13-programa-refugio/47-la-llave-de-laregularizacion-en-panama

EFE (2012, 15 de mayo). ONU alerta vulnerabilidad de refugiados en Ecuador ante redes de trata. Obtenido de El Universo [en línea], disponible en: http:// www.eluniverso.com/2012/05/15/1/1355/onu-alerta-vulnerabilidadrefugiados-ecuador-ante-redes-trata.html

El País (24 de abril de 2015). Valle del Cauca, nueva ruta de tráfico de migrantes cubanos hacia EE.UU. Obtenido de El País - Judicial [en línea], disponible en: http://www.elpais.com.co/elpais/judicial/noticias/valle-cauca-nuevaruta-trafico-migrantes-cubanos-hacia-estados-unidos

El Tiempo (16 de septiembre de 2013). 41 migrantes ilegales, detenidos en Urabá. Obtenido de El Tiempo [en línea], disponible en:http://www.eltiempo. com/archivo/documento/CMs-13065352

El Tiempo (17 de agosto de 2013). En un año, red movió a mil migrantes ilegales. Obtenido de El Tiempo [en línea], disponible en:http://www.eltiempo. com/archivo/documento/CMs-13000551 
El Tiempo (23 de febrero de 2015). De África hasta Colombia, tras el 'sueño americano'. Obtenido de El Tiempo [en línea], disponible en:http://www.eltiempo. $\mathrm{com} /$ politica/justicia/una-travesia-desde-africa-hasta-el- pacíficocolombiano/15283219

El Tiempo (2013). "En 8 años, 3.733 migrantes ilegales han sido detectados" [en línea], disponible en: http://www.eltiempo.com/Multimedia/infografia/ migrantesilegales/

El Tiempo (2015, 4 de enero). "Más de 2 millones de extranjeros entraron al país en 2014" [en línea], disponible en: http://www.eltiempo.com/economia/ sectores/colombia-se-afianza-como-polo-para-los-extranjeros/15052917

Guevara, C. (2014, 28 de septiembre). "Se triplica detección de migrantes indocumentados hacia EE.Uu." [en línea], disponible en:http://www. eltiempo.com/colombia/otras-ciudades/se-triplica-en-colombia-elhallazgo-de-migrantes-indocumentados-que-van-hacia-ee-uu/14602937

Gutiérrez, P. M . (2016). Proliferación, gestión y ¿control? En Fronteras en Colombia como zonas estratégicas: Análisis y perspectivas. Bogotá: Instituto de Ciencia Política Hernán Echavarría Olózaga, pp. 89-113.

Lee, E. S. (1966). "A Theory of Migration”. Demography, Vol. 3, No.1, 47-57.

Lothar, T. y López, P. A. (2011). México: Políticas Públicas beneficiando a los migrantes. Coyoacán: Organización Internacional de las Migraciones de México.

Migración Colombia (2014, diciembre). Comunicado Migración Colombia. From Migración Colombia [en línea], disponible en:http://www. migracioncolombia.gov.co/index.php/es/prensa/comunicados/ comunicados-2014/diciembre-2013/1665-migracion-colombia-y-lapolicia-nacional-detienen-a-37-inmigrantes-ilegales-en-carreteras-denarino

Migración Colombia- orm (2013). Caracterización Sociodemográfica y laboral de los trabajadores temporales extranjeros en Colombia: una mirada retrospectiva. Bogotá: Migración Colombia.

Miller, \& Castle. (2003). The Age of Migration: International Population Movements in the Modern World. 3rd ed, Macmillan.

MinEducación (29 de julio de 2008). Crece presencia en Colombia: Hay cerca de 10.000 chinos en el país. Obtenido de MinEducación [en línea], disponible en:http://www.mineducacion.gov.co/observatorio/1722/article-167102. html 
Ministerio del Interior-Ecuador (2014). Ecuador promueve Política Migratoria Inclusiva y de respeto a los $D D H H$. From Ministerio del Interior-Ecuador [en línea], disponible en:http://www.ministeriointerior.gob.ec/ecuadorpromueve-politica-migratoria-inclusiva-y-de-respeto-a-los-ddhh-2/

Molano-Rojas, A. y Zamara, S. F. (2016). Fronteras: gobernanza, sensibilidad $y$ vulnerabilidad. En Colombia como zonas estratégicas: Análisis y perspectivas. Bogotá Instituto de Ciencia Política Hernan Echavarria Olózaga, pp 17-33.

oeA (2010). Migración Extracontinental en las Américas. Washington D.C.: Organización de los Estados Américanos.

Orjuela, D. B. (2014, 23de junio). "Colombia: en la peligrosa ruta hacia la 'tierra prometida"' [en línea], disponible en: http://www.kienyke.com/historias/ migrantes-ilegales-en-colombia/

Quijano, M. (2006). La migración irregular en Latinoamérica. Guadalajara: Centro de Estudios de Migraciones Internacionales (CEMI).

Ramírez, C. y Mendoza, L. (2013). Perfil Migratorio de Colombia 2012. Bogotá: Organización Internacional para las Migraciones.

Ramos, J. M. (2012). "México - Estados Unidos: Problemas y retos en seguridad fronteriza en la Administración Obama. Revista Región y Sociedad". En Región y Sociedad No. 55. , 5-40.

Sánchez, E. (2015). Tráfico de Inmigrantes en Colombia: Influencia Regional . Bogotá D.C.: Universidad Militar Nueva Granada.

Sanmiguel, I. (2006). Japoneses en Colombia, historia de inmigración, sus descendientes en Japón. En Revista de Estudios Sociales N. 23, 81-96 .

Semana.com (2 de mayo de 2015). "El infierno perdido de los migrantes" [en línea], disponible en: http://www.semana.com/nacion/multimedia/el-infiernoperdido-de-los-migrantes/426329-3

Semanario (2014, 24-julio). "FM4 Paso Libre, asegura: Se necesitan acciones organizadas y coordinadas para ayudar y entender, más que retratar el drama migrante" [en línea], disponible en: http://www.semanario. com.mx/ps/2014/07/fm4-paso-libre-asegura-se-necesitan-accionesorganizadas-y-coordinadas-para-ayudar-y-entender-mas-que-retratar-eldrama-migrante

Senplades (2009). "Plan Nacional Para el Buen Vivir 2009-2013". Quito: Senplades 2009 [en línea], disponible en: http://plan.senplades.gob.ec/migraciones 
Tipanluisa, S. Q. (2011). Políticas Públicas Migratorias en el Ecuador. Quito: Friedrich Ebert Stiftung.

UNODC, y Colombia, M. (2013). Dimensión del Delito de Tráfico de Migrantes en Colombia: realidades institucionales, legales y judiciales . Bogotá D.C.: UNODC. 
